\title{
microRNA-572 functions as an oncogene and a potential biomarker for renal cell carcinoma prognosis
}

\author{
XIANG PAN $^{1-3^{*}}$, ZUWEI LI $^{1,3,4^{*}}$, LIWEN ZHAO $^{1-3}$, JING QUAN $^{1-3}$, LIANG ZHOU $^{1,3,5}$, JINLING XU $^{1}$, \\ WEIJI XU ${ }^{1}$, XIN GUAN $^{1}$, HANG LI $^{1}$, SHANGQI YANG ${ }^{1}$, YAOTING GUI ${ }^{3}$ and YONGQING LAI ${ }^{1,3}$ \\ ${ }^{1}$ Department of Urology, Peking University Shenzhen Hospital, Shenzhen, Guangdong 518036; \\ ${ }^{2}$ Department of Urology, Anhui Medical University, Hefei, Anhui 230032; \\ ${ }^{3}$ The Guangdong and Shenzhen Key Laboratory of Male Reproductive Medicine and Genetics, \\ Peking University Shenzhen Hospital, Institute of Urology of Shenzhen PKU-HKUST Medical Center, Shenzhen, \\ Guangdong 518036; ${ }^{4}$ Department of Urology, Shantou University Medical College, Shantou, Guangdong 515041; \\ ${ }^{5}$ Department of Urology, Guangzhou Medical University, Guangzhou, Guangdong 511436, P.R. China
}

Received January 24, 2018; Accepted August 10, 2018

DOI: $10.3892 / o r .2018 .6649$

\begin{abstract}
Renal cell carcinoma (RCC) is the third most common urological malignancy in the USA and represents $2-3 \%$ of all adult malignancies. Furthermore, the incidence of RCC has been progressively increasing over recent years. Although the morbidity of treatment has decreased with the use of multidisciplinary synthetic therapy, the prognosis of terminal cancer remains poor, with a 5-year survival rate of $5-10 \%$. MicroRNAs (miRs) have been correlated with the regulation of $30-60 \%$ of the proteincoding genes and act as oncogenes or anti-oncogenes in RCC. Considering this research, miRNAs are likely to be the biomarkers for tumor diagnosis, prognosis and the targets for RCC management. In the present study, 42 formalin-fixed paraffin-embedded RCC samples were used. The expression of miR-572 and the role of miR-572 in RCC cell proliferation, migration and apoptosis was determined by performing reverse transcription-quantitative polymerase chain reaction analysis, wound scratch assays, cell proliferation assays, Transwell assays and flow cytometry assays, respectively. Further experiments were conducted to clarify the correlation between miR-572 expression and clinicopathological variables or overall survival. Furthermore, the expression levels of miR-572 were evaluated for the prognosis value of patients with RCC. Upregulation of miR-572 was observed in RCC tissues and RCC cell lines. miR-572 promoted 786-O and ACHN cell proliferation and mobility
\end{abstract}

Correspondence to: Professor Yongqing Lai, Department of Urology, Peking University Shenzhen Hospital, 1120 Lianhua Road, Shenzhen, Guangdong 518036, P.R. China

E-mail: yqlord@163.com

*Contributed equally

Key words: microRNAs, microRNA-572, renal cell carcinoma, oncogene, biomarker and inhibited early apoptosis. In Cox proportional hazard regression analyses, results of the univariate and multivariate analysis indicated that the patients with low miR-572 expression had a significantly longer overall survival compared with the patients with high miR-572 expression (univariate analysis, $\mathrm{P}=0.037$; multivariate analysis, $\mathrm{P}=0.034)$. Results of the Kaplan-Meier survival curves revealed that the patients with downregulated miR-572 have a significantly longer overall survival compared with the patients with highly expressed miR-572 ( $\mathrm{P}=0.019)$. To conclude, the results of the present study suggest that tumor oncogene miR-572 is a potential biomarker for the diagnosis, treatment and prognosis for RCC.

\section{Introduction}

Renal cell carcinoma ( $\mathrm{RCC}$ ) is the third most common urological malignancy in the USA and represents $2-3 \%$ of all adult malignancies. Furthermore, the incidence rate has progressively increased, particularly in young patients and or those with high-grade disease (1-3). In 2017, $\sim 63,990$ cases were diagnosed with kidney and renal pelvis cancer and 14,400 cases were expected to succumb to disease in the USA alone (4). Various risk factors have been associated with RCC, including active and passive cigarette smoking, obesity, hypertension and absent fruit and vegetable consumption (5). Although the morbidity of treatment has decreased with the use of nephron-sparing surgery, laparoscopic and robotic surgery and minimally invasive procedures, and biologic response modifiers are applied to patients with metastatic $\mathrm{RCC}$, the prognosis of terminal cancer remains poor, with a 5 -year survival rate of 5-10\% (6,7). Therefore, it's imperative to identify the clinical and molecular phenotype of occurrence and development of RCC in order to uncover novel targets for the diagnosis, treatment and prognosis of RCC.

MicroRNAs (miRs), which are small noncoding RNA molecules (21-25 bases in length), regulate the gene expression in a sequence-specific manner and promote the suppression of protein synthesis or mRNA degradation (8). The uniqueness 
of miRs is that one miR can regulate numerous protein-coding RNAs (9). In the human genome, miRs have been correlated with the regulation of $30-60 \%$ of protein-coding genes $(10,11)$. Accumulating evidence has suggested that miRs, prominently those upregulated or downregulated in other types of malignancies, act as either oncogenes or anti-oncogenes, respectively, in RCC. For example, miR-367 exerts oncogenic effects in osteosarcoma and promotes the proliferation, migration and invasion of tumor cells with the regulation of DOC-2/DAB2 interactive protein, which was consistent with the oncogenic role of miR-367 in $\operatorname{RCC}(12,13)$.

miR-572 is a type of miR that was recently confirmed to be involved in various types of cancer, including chronic lymphocytic leukemia (14), nasopharyngeal carcinoma (15), ovarian cancer (16) and basal cell carcinoma (17). Results from a study by Wang et al (18) revealed that, compared with corresponding non-tumor controls, miR-572 was markedly elevated in the serum of patients with RCC. However, the expression and the function of miR-572 in RCC remains elusive. Thus, the present study was performed with the purpose of ascertaining the expression of miR-572 in RCC and corresponding normal tissues. Furthermore, the role of miR-572 in the proliferation, apoptosis and prognosis of RCC cell was further explored.

\section{Materials and methods}

Sample collection. RCC tissues $(\mathrm{n}=52)$ and corresponding non-cancerous renal tissues $(n=52)$ from patients that were pathologically diagnosed with RCC and had received no therapy were collected from the Peking University Shenzhen Hospital between January 2016 and June 2017. (Guangdong, China). The corresponding non-cancerous renal tissues were collected $>2 \mathrm{~cm}$ away from the visible tumor range. Written informed consent was obtained from every patient. All the patients were pathologically reviewed and diagnosed with RCC and had not received any chemoradiotherapy. The present study was approved by the Ethics Committees of Peking University Shenzhen Hospital. The collected tissues were checked and classified by hematoxylin and eosin staining. Subsequently, the samples were immersed in RNAlater reagent (Qiagen $\mathrm{GmbH}$, Inc., Hilden, Germany) for $\sim 0.5 \mathrm{~h}$ and stored at $-80^{\circ} \mathrm{C}$. The clinical and pathological information of the patients is presented in Table I.

Formalin-fixed paraffin-embedded (FFPE) tissue specimens. The FFPE RCC samples obtained from the Department of Pathology of Peking University Shenzhen Hospital originated from patients with RCC who had undergone surgery at Peking University Shenzhen Hospital between January 2011 and January 2014. For fixation, all the tissue sample was fixated with $10 \%$ formalin concentration at $4^{\circ} \mathrm{C}$ for $48 \mathrm{~h}$. For RNA extraction, $\sim 10-\mu$ m-thick FFPE sections were used. The clinical and pathological characteristics of the patients, which are presented in Table II, were analyzed on the basis of the 2010 American Joint Committee on Cancer staging system (19). Total RNA of FFPE samples was extracted using an miRNeasy FFPE Kit (Qiagen $\mathrm{GmbH}$, Inc.).

Cell culture and transfection. The cells used in the present study included human embryo kidney cells (293T; Cell Bank of
Table I. Clinicopathological features in patients with renal cell carcinoma.

\begin{tabular}{lc} 
Characteristics & Number of cases \\
\hline Mean age range (years) & $52(27-72)$ \\
Sexual distinction & \\
Male/female & $30 / 18$ \\
Histological type & $39 / 9$ \\
Clear cell/papillary & \\
pT-stage & $27 / 19 / 2$ \\
T1/T2/T3+T4 & \\
Fuhrman grade & $15 / 22 / 8 / 3$ \\
I/II/III/IV & \\
AJCC clinical stages & $27 / 18 / 3$ \\
I/II/III+IV & \\
\hline
\end{tabular}

pT, primary tumor; AJCC, American Joint Committee on Cancer.

Type Culture Collection of the Chinese Academy of Medical Sciences, Shanghai, China) and RCC cell lines (786-O, ACHN and Caki-1; American Type Culture Collection, Manassas, VA, USA). Cells were maintained at $37^{\circ} \mathrm{C}$ in an atmosphere containing $5 \% \mathrm{CO}_{2}$. The composition of the medium was as follows: 89\% Dulbecco's modified Eagle's medium (DMEM; Gibco; Thermo Fisher Scientific, Inc., Waltham, MA, USA), $10 \%$ fetal bovine serum (FBS; Invitrogen; Thermo Fisher Scientific, Inc.), $0.5 \%$ antibiotics $(100 \mu \mathrm{l} / \mathrm{ml}$ penicillin and $100 \mathrm{mg} / \mathrm{ml}$ streptomycin sulfates) and $0.5 \%$ glutamine. A total of 100 pmol miR-572 mimic, inhibitor, negative control (NC) and inhibitor negative control (all Shanghai GenePharma Co., Ltd., Shanghai, China) were transfected into RCC cells for $5 \mathrm{~h}$ using Lipofectamine 2000 reagent (Invitrogen; Thermo Fisher Scientific, Inc.) according to the manufacturer's instructions. Subsequent experiments were performed 24-48 h following transfection. Reverse transcription-quantitative polymerase chain reaction (RT-qPCR) was performed to evaluate the transfected effect. The sequences were presented in Table III.

RNA extraction, cDNA synthesis and RT-qPCR. Total RNA of tissues and cell lines (786-O, ACHN, Caki-1 and 293T) were extracted and purified with the using of TRIzol reagent (Invitrogen; Thermo Fisher Scientific, Inc.) and the RNeasy Maxi Kit (Qiagen $\mathrm{GmbH}$, Inc.), respectively, according to the manufacturer's protocol. For improved experimental results, the extractive RNA samples were measured using a NanoDrop 2000c (Thermo Fisher Scientific, Inc.) to ensure the concentration and the optical density ratio (260/280) of 1.8-2.0 were taken into account. Following this, the eligible RNAs were synthesized to cDNA with the miScript II RT Kit (Qiagen $\mathrm{GmbH}$ ). qPCR reactions were performed to ascertain the expression levels of miR-572 using the Roche LightCycler 480 Real-Time PCR System with a miScript SYBR-Green PCR Kit (Qiagen $\mathrm{GmbH}$ ) under the following conditions: $95^{\circ} \mathrm{C}$ for $1 \mathrm{~min}$, followed by 40 cycles at $95^{\circ} \mathrm{C}$ for $15 \mathrm{sec}, 55^{\circ} \mathrm{C}$ for $30 \mathrm{sec}$ and $72^{\circ} \mathrm{C}$ for $30 \mathrm{sec}$. RNU6B (U6) was used as internal 
Table II. Association between microRNA-572 expression level ${ }^{\mathrm{a}}$ and clinical information in FFPE renal cancer samples.

\begin{tabular}{|c|c|c|c|c|}
\hline \multirow[b]{2}{*}{ Variable } & \multirow[b]{2}{*}{ Total } & \multicolumn{2}{|c|}{ No. of patients (\%) } & \multirow[b]{2}{*}{ P-value } \\
\hline & & $\begin{array}{l}\text { High miR-572 } \\
\text { expression }\end{array}$ & $\begin{array}{l}\text { Low miR-572 } \\
\text { expression }\end{array}$ & \\
\hline \multicolumn{5}{|l|}{$\operatorname{Sex}$} \\
\hline Male & 26 & 14 & 12 & \multirow[t]{2}{*}{0.751} \\
\hline Female & 16 & 7 & 9 & \\
\hline \multicolumn{5}{|c|}{ Age (years) } \\
\hline$\leq 60$ & 33 & 17 & 16 & \multirow[t]{2}{*}{1.000} \\
\hline$>60$ & 9 & 4 & 5 & \\
\hline \multicolumn{5}{|c|}{ Tumor size (cm) } \\
\hline$\leq 4.0$ & 17 & 6 & 11 & \multirow[t]{2}{*}{0.208} \\
\hline$>4.0$ & 25 & 15 & 10 & \\
\hline \multicolumn{5}{|c|}{ Tumor stage } \\
\hline I+ II & 27 & 12 & 15 & \multirow[t]{2}{*}{0.520} \\
\hline III+IV & 15 & 9 & 6 & \\
\hline
\end{tabular}

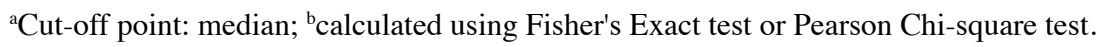

Table III. Sequences of primers and miRs.

\begin{tabular}{lr}
\hline Primer/miR & Sequence \\
\hline miR-572 & F: 5'-GTCCGCTCGGCGGTGGCCCA-3' \\
& R: Universal primers (miScript SYBR-Green \\
& PCR kit) \\
U6 & F: 5'-CTCGCTTCGGCAGCACA-3' \\
& R: 5'-ACGCTTCACGAATTTGCGT-3' \\
miR-572 & F: 5'-GUCCGCUCGGCGGUGGCCCA-3' \\
mimic & R: 5'-GGCCACCGCCGAGCGGACUU-3' \\
miR-572 & 5'-UGGGCCACCGCCGAGCGGAC-3' \\
inhibitor & \\
NC & F: 5'-UUCUCCGAACGUGUCACGUTT-3' \\
& R: 5'-ACGUGACACGUUCGGAGAATT-3' \\
NC inhibitor & 5'-CAGUACUUUUGUGUAGUACAA-3'
\end{tabular}

F, forward; R, reverse; miR, microRNA; NC, negative control; PCR, polymerase chain reaction.

reference for normalization. The primers used in the qPCR are indicated in Table III. Relative expression levels were calculated using the $2^{-\Delta \Delta \mathrm{Cq}}$ method (20).

Wound healing assay. Assessment of the cell migratory aptitude was performed using the wound healing assay. In the assay, a 12-well plate was inoculated with 786-O and ACHN cells $\left(\sim 3 \times 10^{5}\right.$ cells/each well) transfected with miR-572 mimic, inhibitor, NC or inhibitor NC (Shanghai GenePharma, Co., Ltd.). At $6 \mathrm{~h}$ post-transfection, a scratch was introduced using a sterile $200-\mu 1$ pipette tip. Subsequently, the floating cells were washed away using phosphate-buffered saline (PBS; Gibco; Thermo Fisher Scientific, Inc.). At 0, 12 and 24 h, A Leica DMIRB inverted fluorescence microscope (Leica Microsystems GmbH, Wetzlar, Germany) with a digital camera system (Olympus Corporation, Tokyo, Japan) was used to capture images of the scratches.

Cell Counting Kit-8 (CCK-8) assay. Assessment of the proliferation capacity of 786-O and ACHN cells was performed using the CCK-8 assay. A total of 5 pmol of miR-572 mimics, inhibitors, $\mathrm{NC}$ or inhibitor NC was transfected into the cells that had seeded for $24 \mathrm{~h}$ in 96 -well plats with $4 \times 10^{3}$ cells/well. Following gene transfection, $10 \mu \mathrm{l}$ CCK-8 (Everbright lnc., Sayreville, NJ, USA) was added to each well and incubated for $0,24,48$ and $72 \mathrm{~h}$. The optical density value of each well was calculated $1 \mathrm{~h}$ later with an ELISA microplate reader (model 680; Bio-Rad Laboratories, Inc., Hercules, CA, USA) at a wavelength of $490 \mathrm{~nm}$.

Transwell assay. The Transwell assay was used to assess the migratory and invasive aptitude of $\mathrm{ACNH}$ and 786-O cells. According to the manufacturer's recommendation, Transwell chamber inserts (BD Biosciences, New York, NJ, USA) with Matrigel were used to determine cell migration, whereas the inserts without Matrigel were used to assay cell invasion. A total of $200 \mu \mathrm{l}$ serum-free DMEM containing $2 \times 10^{4}$ transfected cells was added into the upper chamber of the inserts, whereas $500 \mu 1$ DMEM with $10 \%$ FBS was added into the lower chamber of the inserts. Following $48 \mathrm{~h}$ of incubation, the cells migrated or invaded to the lower chamber of the inserts were stained with crystal violet at room temperature for $25 \mathrm{~min}$, washed with PBS three times and counted using a microscope under the white light at a magnification of x100 (Leica Microsystems GmbH), successively. 
Flow cytometric assay. Assessment of cell apoptosis rates depended on flow cytometry assay. The cells plated in 6-well plates with $\sim 3 \times 10^{5}$ cells/plate were transfected with 200 pmol of miR-572 mimics, miR-572 inhibitors, NC inhibitor or $\mathrm{NC}$ according to the manufacturer's instructions. Following incubated for $48 \mathrm{~h}$, all cells were harvested, washed by cold PBS twice and re-suspended in $100 \mu 1 \mathrm{X}$ binding buffer. Subsequently, the re-suspended cells were mixed with $5 \mu 1$ propidium iodide (Invitrogen; Thermo Fisher Scientific, Inc.) and $5 \mu \mathrm{l}$ Annexin V-fluorescein isothiocyanate (Invitrogen; Thermo Fisher Scientific, Inc.), and cultured in darkness at room temperature for $15 \mathrm{~min}$. Each tube was treated with $400 \mu \mathrm{l}$ binding buffer. The apoptotic rates were measured using a flow cytometer (EPICS, Xl-4; Beckman Coulter, Inc., Brea, CA, USA). FlowJo software (version, X; FlowJo LLC, Ashland, OR, USA) was used for data analysis.

Statistical analysis. All assays were repeated three times. All statistical analysis was executed with the use of SPSS 19.0 (IBM Corp., Armonk, NY, USA). Paired Student's t-test was applied to assess the significance of the differences between two groups of data in matched tumor and non-cancerous tissues. The significance between cell lines was analyzing using one-way analysis of variance and Dunnett's post hoc test. Student's t-test was used the analysis of assays for characterizing phenotypes of cells. Analysis of the correlation between miR-572 expression and clinicopathological variables was performed using Fisher's exact test or Pearson's $\chi^{2}$ test. The univariate and multivariate levels between miR-572 expression and clinicopathological variables or survival were determined using Cox proportional hazard regression analysis. The survival curves were plotted with Kaplan-Meier curves. The log-rank test was applied to evaluate the differences between these curves. $\mathrm{P}<0.05$ was considered to indicate a statistically significant difference.

\section{Results}

Upregulation of miR-572 was observed in RCC tissues and cell lines. RT-qPCR was performed with 52 pairs of RCC tissues and corresponding non-cancerous renal tissues with the purpose of exploring the clinical association of miR-572 in RCC. As indicated in Fig. 1A, the relative expression levels of miR-572 in 52 paired tissues $[\log 2(\mathrm{~T} / \mathrm{N})])$ were demonstrated and a total of $39 \mathrm{RCC}$ tissues exhibited upregulation of miR-572. Fig. 1B indicated the mean expression of miR-572 and the results suggested that miR-572 was significantly upregulated in RCC tissues $(5.515 \pm 0.263)$ compared with corresponding non-cancerous renal tissues (1.000 0.179 ; $\mathrm{P}<0.001)$. The relative expression levels of miR-572 in RCC cell lines (786-O, Caki-1 and ACHN) and 293T cell lines were also assessed (Fig. 1C). The results indicated that the expression levels of miR-572 were significantly increased in RCC cell lines (786-O, 8.084 $\pm 0.618, \mathrm{P}<0.01$; ACHN, 9.372 \pm 1.371 , $\mathrm{P}<0.01$; and Caki-1, 4.643 $\pm 0.793, \mathrm{P}<0.05)$ compared with $293 \mathrm{~T}$ cells $(1.000 \pm 0.265)$. These results indicated that miR-572 may be up regulated in RCC tissues and possibly functions as an oncogene in RCC.

Validation of cell transfection efficiency. As indicated in Fig. 1C, the expression of miR-572 in ACHN and 780-O was most different from 293T. Subsequently, ACHN and 7800 cells were selected for analysis in further functional assays. Validation of the transfection efficiency of miR-572 mimic or inhibitor was assessed using RT-qPCR. The outcomes revealed that the expression levels of miR-572 in cells transfected with miR-572 mimic were 79.893 times higher (786-O cells, $\mathrm{P}<0.01)$ and 67.649 times higher $(\mathrm{ACHN}$ cells, $\mathrm{P}<0.01)$ compared with NC. The expression levels of miR-572 in cells transfected with miR-572 inhibitor exhibited the opposite effect and were 0.119 times higher $(786-\mathrm{O}$ cells, $\mathrm{P}<0.05)$ and 0.418 times higher $(\mathrm{ACHN}$ cells, $\mathrm{P}<0.05)$ compared with $\mathrm{NC}$ inhibitor (Fig. 1D).

miR-572 promotes cell proliferation. The role of miR-572 in cell proliferation was investigated using the CCK-8 assay. The outcomes indicated that the proliferation of 786-O significantly increased by $33.74 \%(\mathrm{P}<0.01), 37.58 \%(\mathrm{P}<0.01)$ and $24.72 \%(\mathrm{P}<0.001)$ following transfection with miR-572 mimic compared with NC. However, proliferation was significantly decreased by $25.18 \%(\mathrm{P}<0.05), 33.90 \%(\mathrm{P}<0.001)$ and $10.01 \%(\mathrm{P}<0.001)$ following transfection with $\mathrm{miR}-572$ inhibitor compared with NC inhibitor at 24, 48 and $72 \mathrm{~h}$ (Fig. 2A and B). Similar outcomes were obtained for ACHN cells. Notably, the proliferation was significantly increased by $30.99 \%(\mathrm{P}<0.01), 32.39 \%(\mathrm{P}<0.001), 16.27 \%(\mathrm{P}<0.001)$ but significantly decreased by $79.54 \%(\mathrm{P}<0.01), 3.37 \%(\mathrm{P}<0.01)$, $57.70 \%(\mathrm{P}<0.001)$ at 24,48 and $72 \mathrm{~h}$ following transfection with $\mathrm{miR}-572 \mathrm{mimic}$ or inhibitor compared with the respective NC (Fig. 2C and D). These outcomes demonstrated that miR-572 may promote cell proliferation.

miR-572 promotes cell mobility. Assessment of the role of miR-572 of cell mobility was performed using wound healing assays and Transwell assays (Figs. 3 and 4). In the wound healing assay (Fig. 3A), 786-O and ACHN cells transfected with miR-572 mimic exhibited significantly increased migration compared with NC (Fig. 3B and C; $786-\mathrm{O}, 1.862 \pm 0.096$ vs. $1.000 \pm 0.092, \mathrm{P}<0.01$; $\mathrm{ACHN}$, $1.589 \pm 0.038$ vs. $1.000 \pm 0.038, \mathrm{P}<0.01)$, whereas transfection with miR-572 inhibitor had an opposite result when compared with NC (Fig. 3B and C; 786-O, 0.756 \pm 0.052 vs. $1.000 \pm 0.079$, $\mathrm{P}<0.05$; ACHN, $0.609 \pm 0.034$ vs. $1.000 \pm 0.051, \mathrm{P}<0.05)$. In the Transwell assay (Fig. 4A), the number of relative migratory 786-O and ACHN cells per field was significantly increased following treatment with miR-572 mimic (Fig. 4C; $786-\mathrm{O}, 1.717 \pm 0.053$ vs. $1.000 \pm 0.046, \mathrm{P}<0.01$; Fig. $4 \mathrm{E}$; $\mathrm{ACHN}, 1.642 \pm 0.064$ vs. $1.000 \pm 0.060, \mathrm{P}<0.001)$. However, the number of migratory cells was significantly decreased following treatment with miR-572 inhibitor (Fig. 4C and E, respectively; 786-O, $0.656 \pm 0.060$ vs. $1.000 \pm 0.079, \mathrm{P}<0.05$; and $\mathrm{ACHN}, 0.609 \pm 0.070$ vs. $1.000 \pm 0.062, \mathrm{P}<0.05)$. Notably, elevated levels of miR-572 significantly promoted cell invasion compared with the NC (Fig. 4B; 786-O, 1.626 \pm 0.048 vs. $1.000 \pm 0.133, \mathrm{P}<0.05$; Fig. $4 \mathrm{D} ; \mathrm{ACHN}, 1.667 \pm 0.043$ vs. $1.000 \pm 0.074, \mathrm{P}<0.01$ ), whereas these effects were significantly reversed by miR-572 inhibitor when compared with $\mathrm{NC}$ inhibitor (Fig. 4B, 786-O, $0.680 \pm 0.065$ vs. $1.000 \pm 0.043, \mathrm{P}<0.05$; Fig. 4D; ACHN, $0.635 \pm 0.091$ vs. $1.000 \pm 0.047, \mathrm{P}<0.01)$. These outcomes demonstrated that miR-572 may promote cell mobility. 

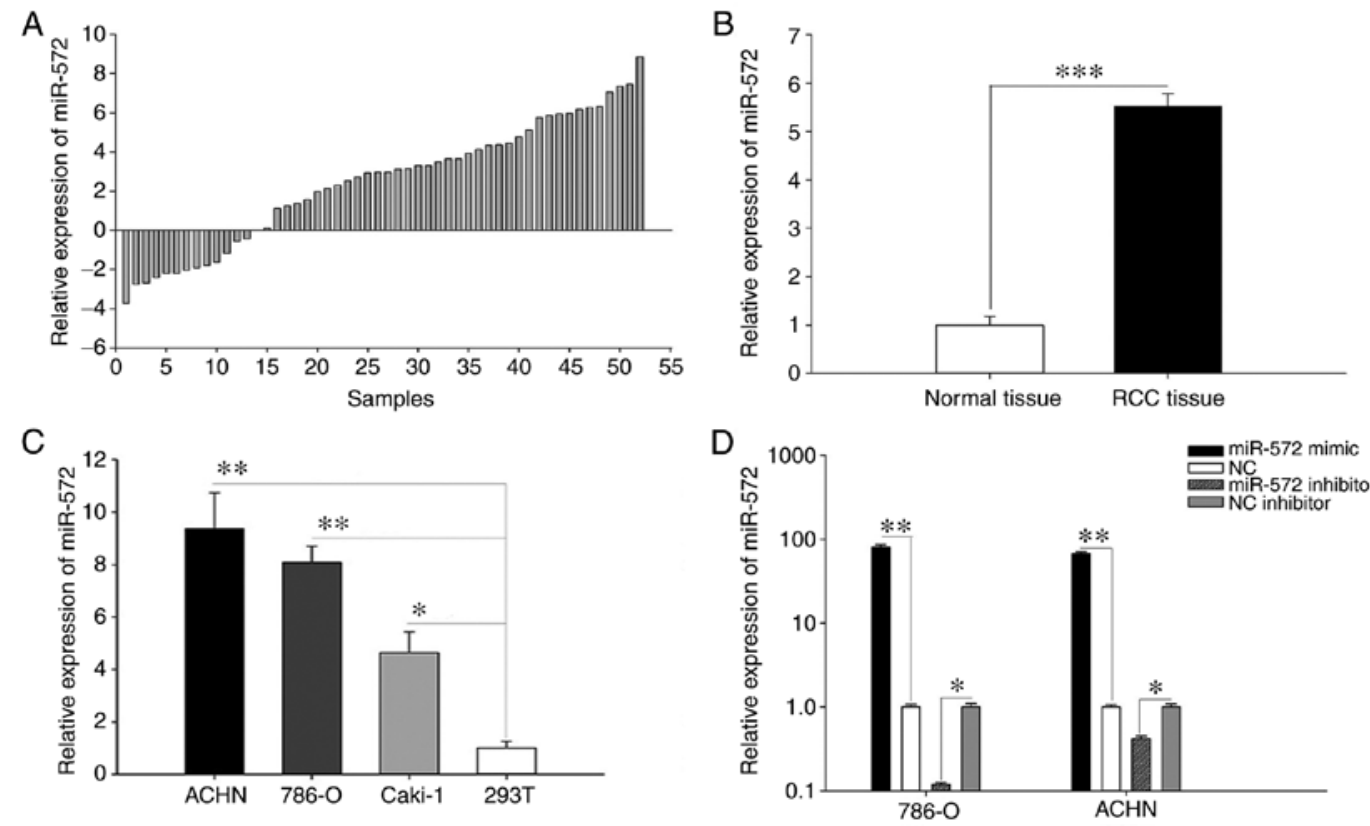

Figure 1. (A) Relative expression levels of miR-572 in 52 paired tissues [ $\log 2(\mathrm{~T} / \mathrm{N})]$. (B) The mean expression levels of miR-572 in RCC tissues were significantly increased compared with corresponding non-cancerous renal tissues. (C) Upregulated expression levels of miR-572 were observed in 786-O, ACHN and Caki-1 cell lines compared with $293 \mathrm{~T}$ cell lines. (D) The relative expression levels of miR-572 post-transfection in 786-O and ACHN cell lines. "P<0.05, ${ }^{* *} \mathrm{P}<0.01,{ }^{* * *} \mathrm{P}<0.001$ as indicated. NC, negative control; miR, microRNA.
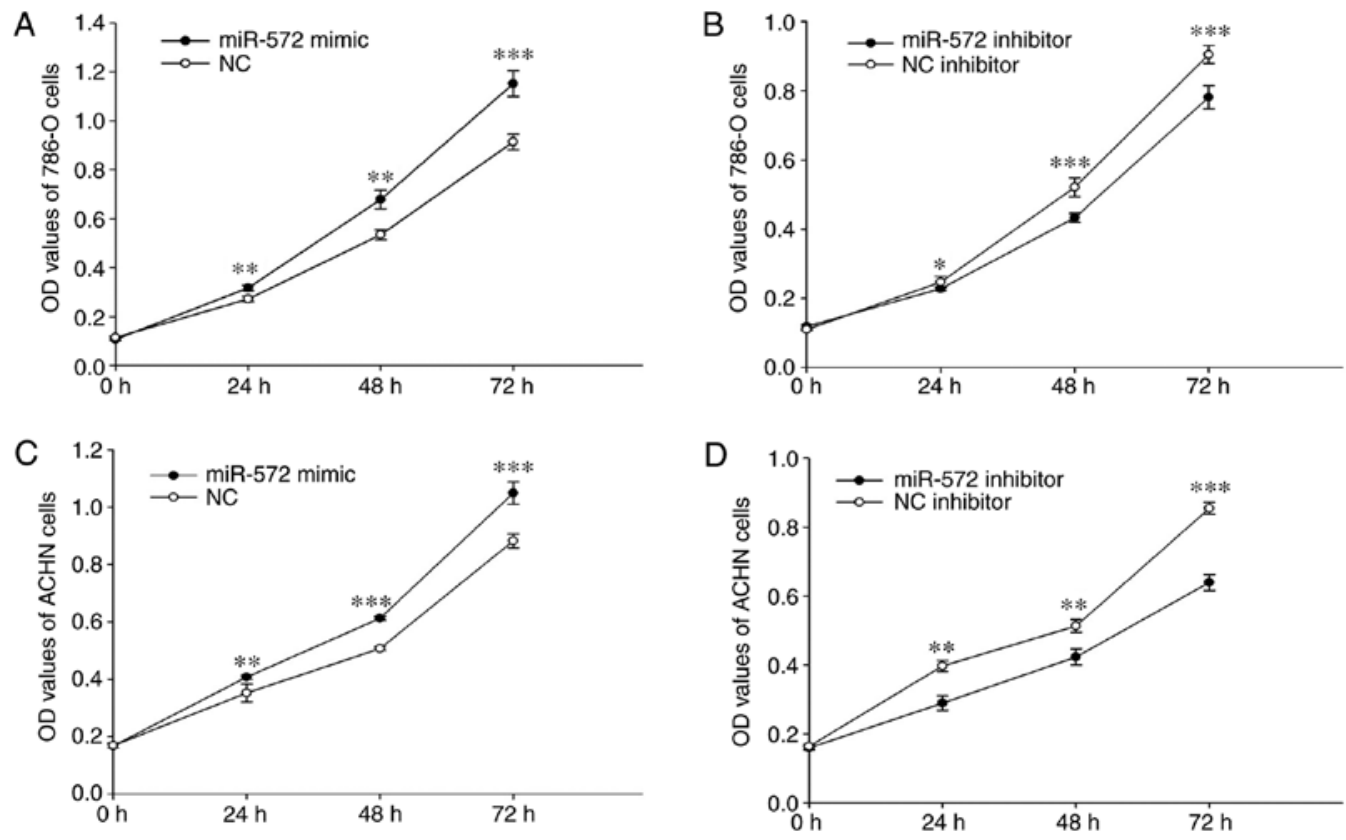

Figure 2. Assessment of the ability of miR-572 in cell proliferation using the CCK-8 assay. (A) Upregulation of miR-572 promoted 786-O cell proliferation whereas (B) downregulation of miR-572 inhibited 786-O cell proliferation. (C and D) Similar effects were obtained in ACHN cell. " $\mathrm{P}<0.05,{ }^{* *} \mathrm{P}<0.01$, ${ }^{* * * *} \mathrm{P}<0.001$ vs. miR-572 mimic or inhibitor. NC, negative control; OD, optical density; CCK-8, Cell Counting Kit-8; miR-572, microRNA-572.

miR-572 inhibits early apoptosis in cells. Assessment of cell apoptosis was performed using flow cytometry. Elevated levels of miR-572 significantly inhibited cell early apoptosis compared with NC (786-O, $4.73 \pm 0.635 \%$ vs. $10.17 \pm 0.404 \%$, $\mathrm{P}<0.001$; ACHN, $4.52 \pm 0.800 \%$ vs. $10.22 \pm 0.595 \%, \mathrm{P}<0.01$ ), whereas these effects could be significantly reversed by miR-572 inhibitor (786-O, $18.87 \pm 0.862 \%$ vs. $10.26 \pm 0.530 \%$, $\mathrm{P}<0.001$; ACHN, $10.30 \pm 0.367 \%$ vs. $18.96 \pm 0.306 \%, \mathrm{P}<0.001$;
Fig. 5). These outcomes demonstrated that miR-572 may inhibit early apoptosis in cells.

miR-572 serves as a potential independent prognostic marker for $R C C$. The association between the expression levels of miR-572 and clinicopathological variables or overall survival was analyzed with the FFPE renal cancer samples. As presented in Table II, no significant difference was observed 


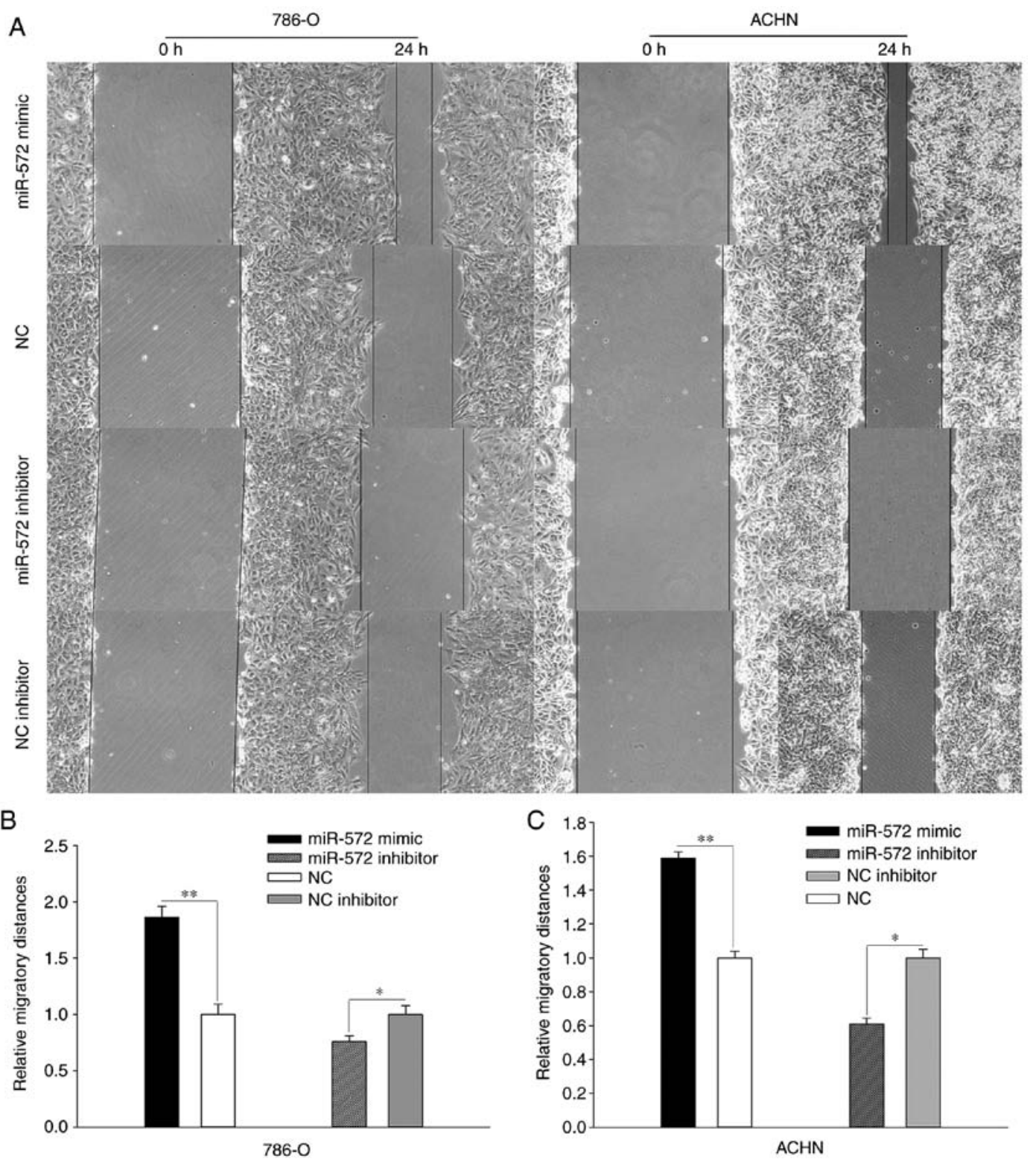

Figure 3. Assessment of cell mobility using the wound healing assay. (A) Images of the scratches (magnification, x100). (B) Upregulation of miR-572 promoted 786-O cell migration whereas downregulation of miR-572 inhibited 786-O cell proliferation. (C) Similar effects were obtained in ACHN cells. "P $<0.05$, ${ }^{* * *} \mathrm{P}<0.01$ as indicated. NC, negative control; miR-572, microRNA-572.

Table IV. miR-572 expression and patients' survival.

\begin{tabular}{|c|c|c|c|c|}
\hline \multirow[b]{2}{*}{ Variable } & \multicolumn{2}{|c|}{ Univariate analysis } & \multicolumn{2}{|c|}{ Multivariate analysis } \\
\hline & HR $(95 \%$ CI $)$ & P-value & $\mathrm{HR}(95 \% \mathrm{CI})$ & P-value \\
\hline Sex (female vs. male) & $2.037(0.537-7.720)$ & 0.295 & $4.672(0.830-26.287)$ & 0.080 \\
\hline Age ( $\leq 60$ vs. $>60$ years) & $0.760(0.164-3.519)$ & 0.726 & $2.054(0.301-14.012)$ & 0.462 \\
\hline Tumor size $(\leq 4.0 \mathrm{vs} .>4.0 \mathrm{~cm})$ & $8.458(1.081-66.188)$ & 0.042 & $10.184(1.213-85.507)$ & 0.033 \\
\hline Tumor stage (I+II vs. III+IV) & $1.014(0.296-3.473)$ & 0.982 & $0.415(0.112-1.533)$ & 0.187 \\
\hline miR-572 (low vs. high expression) & $0.195(0.042-0.903)$ & 0.037 & $0.174(0.034-0.878)$ & 0.034 \\
\hline
\end{tabular}

HR, hazard ratio; 95\% CI, 95\% confidence interval; miR-572, microRNA-572.

between miR-572 expression level and sex, age, tumor size and tumor stage. However, univariate analysis (Fig. 6A) suggested that the expression level of miR-572 was inversely correlated with overall survival $(\mathrm{HR}=0.195,95 \% \mathrm{CI}=0.042-0.903$, $\mathrm{P}=0.037$; Table IV). Similar outcomes were indicated in the survival curves of Cox proportional hazard regression 


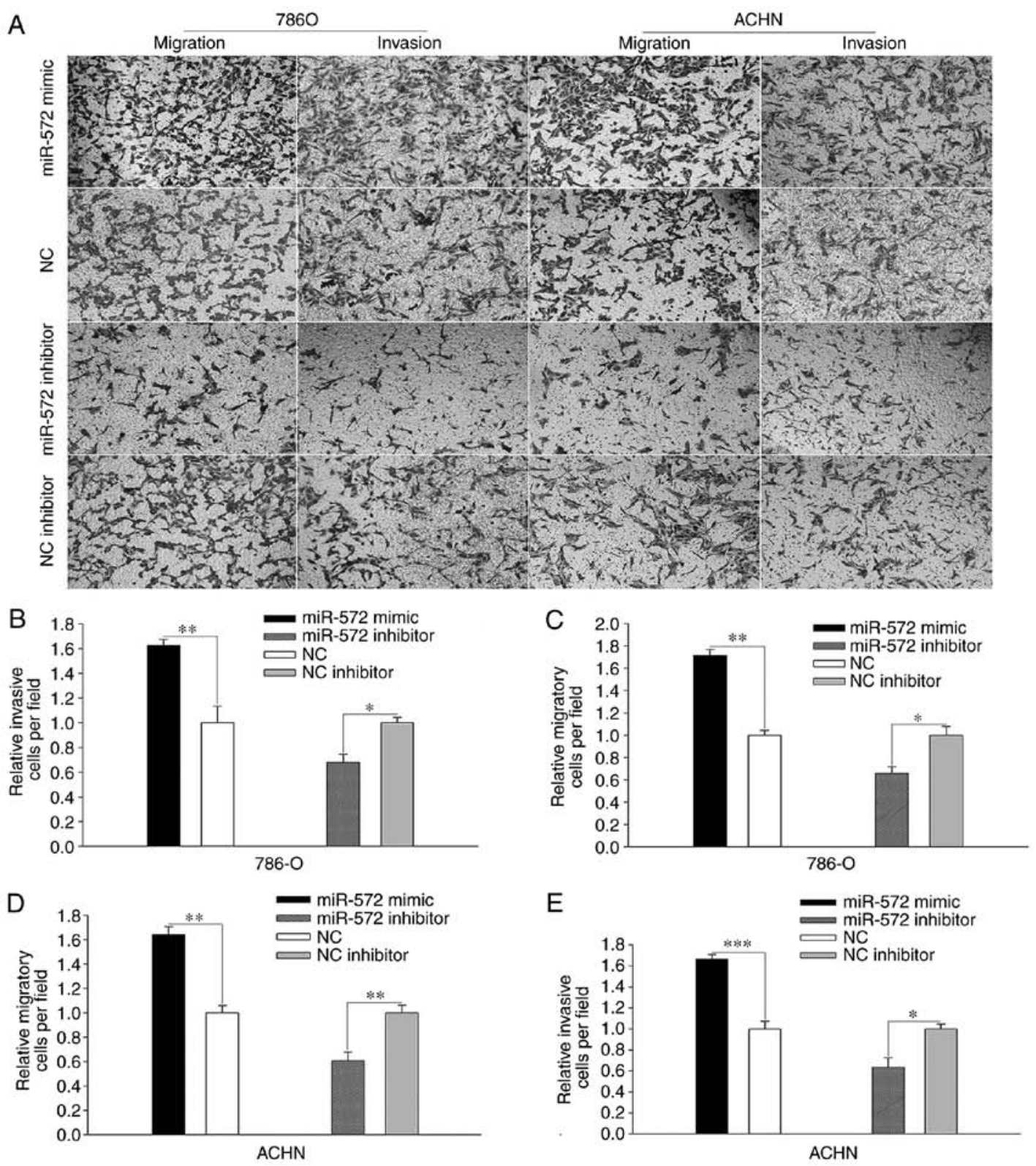

Figure 4. Assessment of the ability of miR-572 of cell mobility using Transwell assays. (A) Images of migratory and invasive 786-O and ACHN cells (magnification, $x 100$ ). (B and C) Upregulation of miR-572 promoted 786-O cell migration and invasion. (D and E) Similar effects were obtained in ACHN cells. ${ }^{*} \mathrm{P}<0.05,{ }^{* *} \mathrm{P}<0.01,{ }^{* * *} \mathrm{P}<0.001$ as indicated. NC, negative control; miR-572, microRNA-572.

analysis (Fig. 6B), which suggested that the patients with low miR-572 expression levels had a significantly increased overall survival after adjusting for sex, age, tumor size and tumor stage in the multivariate analysis $(\mathrm{HR}=0.174,95 \%$ $\mathrm{CI}=0.034-0.878, \mathrm{P}=0.034$; Table IV). Furthermore, data of the Kaplan-Meier survival curves demonstrated that the patients with low expression of miR-572 had a significantly longer overall survival ( $\mathrm{P}=0.019$, Fig. $6 \mathrm{C})$. These outcomes demonstrated that miR-572 may serve as a potential independent prognostic marker for RCC.

\section{Discussion}

RCC, which accounts for the 7th and the 9th most common malignancy in men and women worldwide, respectively, gives rise to $\sim 20,9000$ new cases and 102,000 fatalities every year $(5,21)$. There is a general consent that modulation of miR expression serves a momentous role in oncogene and anti-oncogene proteins by mediating their effects (22). miRs have been indicated to be implicated in numerous biological processes, including proliferation, apoptosis, metabolic reprogramming and pluripotency (23). In recent years, an increasing number of tumor signaling pathways that interact with miRs were revealed to be associated with RCC, including the HIF-1 signaling pathway, mTOR signaling pathway and c-MET signaling pathway (24). Results from Dey et al (25) demonstrated that miR-21 functions as an oncogene in RCC and overexpression of miR-21 increases tumor cell proliferation and invasion via Akt/TORC1 signaling. Another study revealed that the oncomir miR-23b promotes kidney tumor growth by inhibiting proline oxidase, which functions as a mitochondrial tumor suppressor by decreasing hypoxia-inducible factor signaling (26). 
A
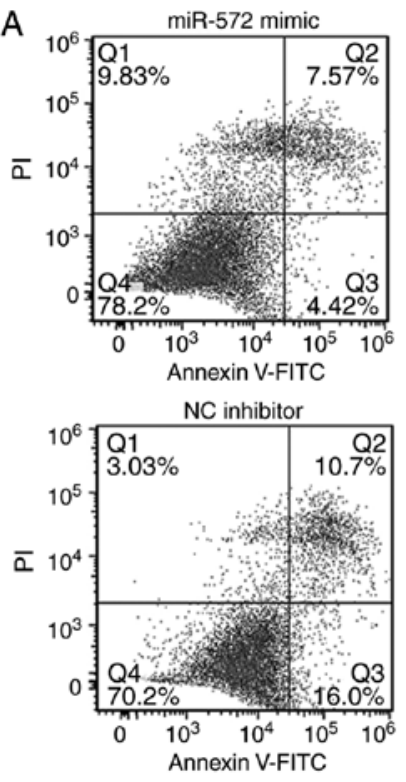

B
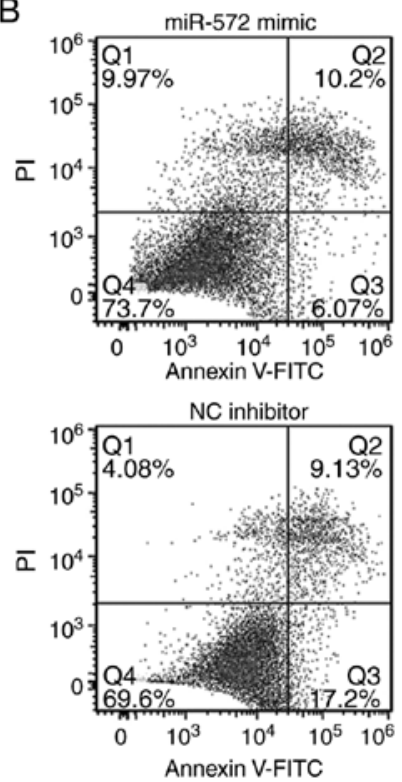

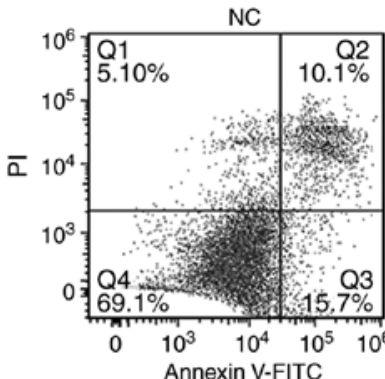

Annexin V-FITC
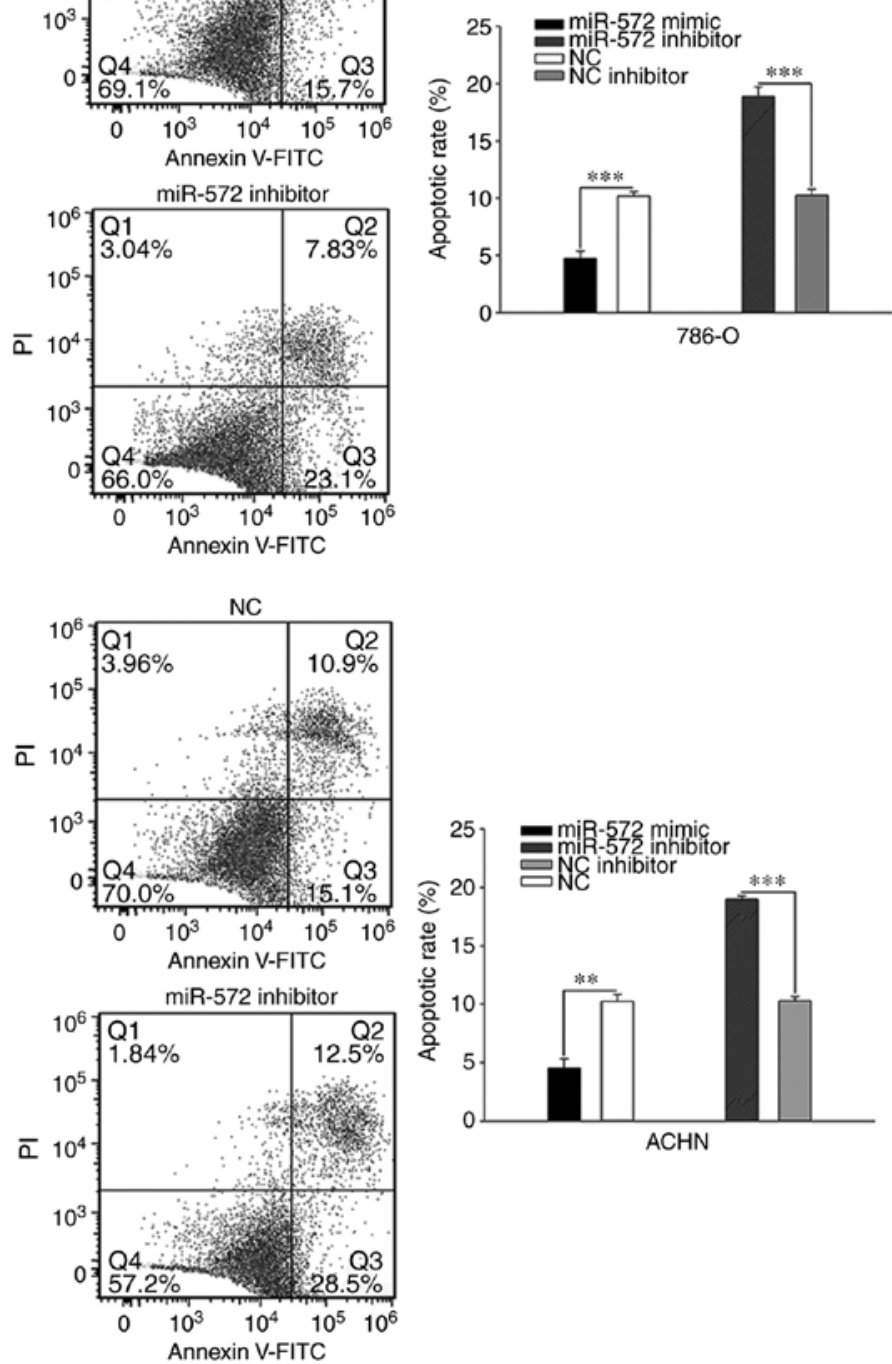

Figure 5. Assessment of cell apoptosis using the flow cytometry assay. Upregulation of miR-572 inhibited (A) 786-O and (B) ACHN cell apoptosis; however, these effects were reversed following the downregulation of miR-572 expression. ${ }^{* *} \mathrm{P}<0.01,{ }^{* * *} \mathrm{P}<0.001$ as indicated. NC, negative control; miR-572, microRNA-572; PI, propidium iodide; FITC, fluorescein isothiocyanate.

Accumulating evidence has suggested that miRs serve an irreplaceable role in the genesis and development of RCC. For example, tumor suppressor miR-338-3p suppresses the expression of ALK5 in RCC, which results in the inhibition of cell invasion (27). Furthermore, miR-766-3p, mediated by DNA-methylation, attenuates the proliferation ability of RCC and overexpression of miR-766-3p is associated with clinical stage and poor survival (28). Circulating miR-572 has been demonstrated to be significantly increased in RCC by TaqMan Low Density Array and RT-qPCR analysis in a previous study (18). However, the expression and roles of miR-572 in RCC tissues and cell lines remain unclear.

In the present study, results of RT-qPCR suggested that the expression of miR-572 in RCC tissues and 786-O and ACHN cells was significantly increased compared with that in corresponding non-cancerous renal tissues and 293T cells, respectively. These result are in accordance with the expression levels of miR-572 determined in nasopharyngeal carcinoma (15), ovarian cancer (16) and human neuroblastoma (29). Further experiments with wound healing assays, CCK-8 assays, Transwell assays and flow cytometric assays suggested that overexpression of miR-572 results in a positive effect on RCC cell proliferation, migration and invasion and inhibition of early apoptosis, respectively. Notably, opposite effects were observed in the case of suppressing the expression of miR-572, suggesting that miR-572 functions as an oncogene in RCC. Further prognostic analysis demonstrated that patients with downregulated miR-572 had a significantly longer overall survival, suggesting miR-572 may be a promising independent prognostic marker for RCC.

The molecular mechanisms concerning miR-572 in mediating the genesis and development of tumors are well 

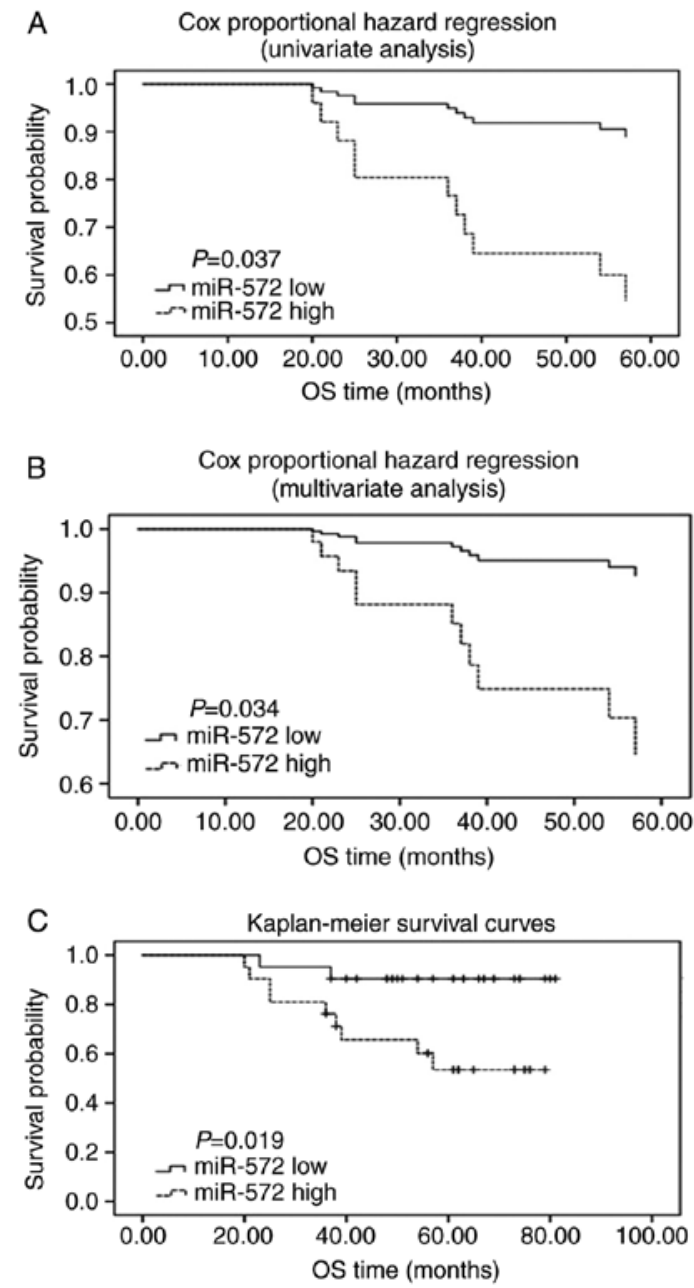

Figure 6. Survival curves of Cox proportional hazard regression analysis. (A) Results of univariate analysis indicated that patients with downregulated miR-572 had a significantly increased overall survival.(B) Similar results were obtained regarding multivariate analysis. (C) Results of the Kaplan-Meier survival curves suggested that patients with downregulated miR-572 had a significantly increased overall survival. miR-572, microRNA-572; OS, overall survival.

documented in numerous types of cancer and diseases. Results from Yu et al (30) provided evidence that miRNA-572 accelerates the recovery of early post-operative cognitive dysfunction by means of inhibiting neural cell adhesion molecule1. In human ovarian cancer, miR-572 was revealed to be upregulated in cancer tissues as well as cell lines, which was associated with poor prognosis (31). Furthermore, miRNA-572 was indicated to directly inhibit SOCS1 and p21, which promoted the proliferation of ovarian cancer cells (31). In another study concerning ovarian cancer, suppression of PPP2R2C expression made miR-572 conducive to tumor cell proliferation, which suggests that miR-572 may be a target for treating ovarian cancer (16). Similarly, Yan et al (15) demonstrated that overexpression of miR-572 and downregulation of PPP2R2C had the same effect on nasopharyngeal carcinoma (accelerated nasopharyngeal carcinoma cell proliferation and invasion). Furthermore, this study indicated that miR-572 binds to the 3 -untranslated region of PPP2R2C, leading to the inhibition of its expression, which suggests that miR-572 exerts its functions by downregulating PPP2R2C.
The molecular mechanism mediated by miR-572 in RCC will be explored in our future study. To understand the molecular mechanism of miR-572 in RCC, two databases (targetScan and miRWalk) will be used and three genes (PPP2R2C, CIB2 and BAG1) will be selected as potential targets that are regulated by miR-572.

In conclusion, upregulation of miR-572 was indicated in RCC tissues and cell lines. Further experiments revealed that overexpression of miR-572 results in a positive effect on the proliferation, migration and invasion of cells and inhibition of early apoptosis, which suggests that miR-572 acts as oncogene in RCC. Further prognostic analysis demonstrated that patients with downregulated miR-572 expression have a significantly reduced overall survival, which suggests that miR-572 may be a promising independent prognostic marker for RCC.

\section{Acknowledgements}

Not applicable.

\section{Funding}

The present study was supported by the Science and Technology Development Fund Project of Shenzhen (grant no. JCYJ20170307111334308), Clinical Research Project of Shenzhen Health Commission (grant no. SZLY2018023) and the Fund of 'San-ming' Project of Medicine in Shenzhen (grant no. SZSM201612066).

\section{Availability of data and materials}

All data generated or analyzed during this study are included in this published article.

\section{Authors' contributions}

XP and ZL performed experimental work (RT-qPCR, wound scratch assay, cell proliferatin assay, Transwell assay and flow cytometry assay) and aided in writing the manuscript. LiwZ collected tissue samples. JQ, LiaZ and JX designed the study, coordinated the molecular biology experiment and assisted in writing the manuscript. WX, XG and HL designed the study and observed the patients. SY designed the study, recruited patients and examined controls. YG extracted the total RNA from the FFPE samples. YL collected tissue samples and edited the manuscript. All authors read and approved the final manuscript.

\section{Ethics approval and consent to participate}

The study was approved by the Ethics Committee of Peking University Shenzhen Hospital (Shenzhen, China).

\section{Patient consent for publication}

Written informed consent was obtained from all patients for publication of data.

\section{Competing interests}

The authors declare that they have no competing interests. 


\section{References}

1. Petrozza V, Pastore AL, Palleschi G, Tito C, Porta N, Ricci S, Marigliano C, Costantini M, Simone G, Di Carlo A, et al: Secreted miR-210-3p as non-invasive biomarker in clear cell renal cell carcinoma. Oncotarget 8: 69551-69558, 2017.

2. Siegel R, Naishadham D and Jemal A: Cancer statistics, 2013. CA Cancer J Clin 63: 11-30, 2013.

3. King SC, Pollack LA, Li J, King JB and Master VA: Continued increase in incidence of renal cell carcinoma, especially in young patients and high grade disease: United States 2001 to 2010 J Urol 191: 1665-1670, 2014.

4. Siegel RL, Miller KD and Jemal A: Cancer statistics, 2017. CA Cancer J Clin 67: 7-30, 2017.

5. Rini BI, Campbell SC and Escudier B: Renal cell carcinoma. Lancet 373: 1119-1132, 2009.

6. Patel C, Ahmed A and Ellsworth P: Renal cell carcinoma: A reappraisal. Urol Nurs 32: 182-190; quiz 191, 2012.

7. Hadoux J, Vignot S and De La Motte Rouge T: Renal cell carcinoma: Focus on safety and efficacy of temsirolimus. Clin Med Insights Oncol 4: 143-154, 2010.

8. Homami A and Ghazi F: MicroRNAs as biomarkers associated with bladder cancer. Med J Islamic Repub Iran 30: 475, 2016.

9. Enokida H, Yoshino H, Matsushita R and Nakagawa M: The role of microRNAs in bladder cancer. Investig Clin Urol 1 (Suppl 57): S60-S76, 2016.

10. Filipowicz W, Bhattacharyya SN and Sonenberg N: Mechanisms of post-transcriptional regulation by microRNAs: Are the answers in sight? Nat Rev Genet 9: 102-114, 2008.

11. Hobert O: Gene regulation by transcription factors and microRNAs. Science 319: 1785-1786, 2008

12. Ding D, Zhang Y, Wen L, Fu J, Bai X, Fan Y, Lin Y, Dai H, Li Q, Zhang Y, et al: MiR-367 regulates cell proliferation and metastasis by targeting metastasis-associated protein 3 (MTA3) in clear-cell renal cell carcinoma. Oncotarget 8: 63084-63095, 2017.

13. Cai W, Jiang H, Yu Y, Xu Y, Zuo W, Wang S and Su Z: mi $R-367$ regulation of DOC-2/DAB2 interactive protein promotes proliferation, migration and invasion of osteosarcoma cells. Biomed Pharmacother 95: 120-128, 2017.

14. Zhu DX, Zhu W, Fang C, Fan L, Zou ZJ, Wang YH, Liu P, Hong M, Miao KR, Liu P, et al: miR-181a/b significantly enhances drug sensitivity in chronic lymphocytic leukemia cells via targeting multiple anti-apoptosis genes. Carcinogenesis 33 1294-1301, 2012.

15. Yan L, Cai K, Liang J, Liu H, Liu Y and Gui J: Interaction between miR-572 and PPP2R2C, and their effects on the proliferation, migration, and invasion of nasopharyngeal carcinoma (NPC) cells. Biochem Cell Biol 95: 578-584, 2017.

16. Wu AH, Huang YL, Zhang LZ, Tian G, Liao QZ and Chen SL: MiR-572 prompted cell proliferation of human ovarian cancer cells by suppressing PPP2R2C expression. Biomed Pharmacother 77: 92-97, 2016.
17. Sand M, Skrygan M, Sand D, Georgas D, Hahn SA, Gambichler T, Altmeyer P and Bechara FG: Expression of microRNAs in basal cell carcinoma. Br J Dermatol 167: 847-855, 2012.

18. Wang L, Tian H, Yuan J, Wu H, Wu J and Zhu X: CONSORT: Sam68 is directly regulated by MiR-204 and promotes the self-renewal potential of breast cancer cells by activating the wnt/beta-catenin signaling pathway. Medicine 94: e2228, 2015.

19. Edge SB and Compton CC: The American Joint Committee on Cancer: The 7th edition of the AJCC cancer staging manual and the future of TNM. Ann surg Oncol 17: 1471-1474, 2010.

20. Livak KJ and Schmittgen TD: Analysis of relative gene expression data using real-time quantitative PCR and the $2^{-\Delta \Delta C_{\mathrm{T}}}$ method. Methods 25: 402-408, 2001.

21. Gupta K, Miller JD, Li JZ, Russell MW and Charbonneau C: Epidemiologic and socioeconomic burden of metastatic renal cell carcinoma (mRCC): A literature review. Cancer Treat Rev 34: 193-205, 2008.

22. Kong YW, Ferland-McCollough D, Jackson TJ and Bushell M: microRNAs in cancer management. Lancet Oncol 13: e249-258, 2012.

23. Hatziapostolou M, Polytarchou C and Iliopoulos D: miRNAs link metabolic reprogramming to oncogenesis. Trends Endocrinol Metab 24: 361-373, 2013.

24. Sellitti DF and Doi SQ: MicroRNAs in renal cell carcinoma. Microrna 4: 26-35, 2015.

25. Dey N, Das F, Ghosh-Choudhury N, Mandal CC, Parekh DJ, Block K, Kasinath BS, Abboud HE and Choudhury GG: microR NA-21 governs TORC1 activation in renal cancer cell proliferation and invasion. PLoS One 7: e37366, 2012.

26. Liu W, Zabirnyk O, Wang H, Shiao YH, Nickerson ML, Khalil S, Anderson LM, Perantoni AO and Phang JM: miR-23b* targets proline oxidase, a novel tumor suppressor protein in renal cancer. Oncogene 29: 4914-4924, 2010.

27. Zhang X, Wang C, Li H, Niu X, Liu X, Pei D, Guo X, Xu X and $\mathrm{Li}$ Y: miR-338-3p inhibits the invasion of renal cell carcinoma by downregulation of ALK5. Oncotarget 8: 64106-64113, 2017.

28. Chen C, Xue S, Zhang J, Chen W, Gong D, Zheng J, Ma J, Xue W, Chen Y, Zhai W, et al: DNA-methylation-mediated repression of miR-766-3p promotes cell proliferation via targeting SF2 expression in renal cell carcinoma. Int J Cancer 141: 1867-1878, 2017.

29. Mundalil Vasu M, Anitha A, Takahashi T, Thanseem I, Iwata K, Asakawa T and Suzuki K: Fluoxetine increases the expression of miR-572 and miR-663a in human neuroblastoma cell lines. PLoS One 11: e0164425, 2016

30. Yu X, Liu S, Li J, Fan X, Chen Y, Bi X, Liu S and Deng X: MicroRNA-572 improves early post-operative cognitive dysfunction by down-regulating neural cell adhesion molecule 1. PLoS One 10: e0118511, 2015

31. Zhang X, Liu J, Zang D, Wu S, Liu A, Zhu J, Wu G, Li J and Jiang L: Upregulation of miR-572 transcriptionally suppresses SOCS1 and p21 and contributes to human ovarian cancer progression. Oncotarget 6: 15180-15193, 2015. 